\title{
INFLUÊNCIA DA IDADE E ALTITUDE NAS CARACTERÍSTICAS ANATÔMICAS, QUÍMICAS E DE DENSIDADE BÁSICA DA MADEIRA DE CANDEIA - Eremanthus erythropappus
}

\author{
Cláudia Lopes Selvati de Oliveira Mori ${ }^{1}$, José Otávio Brito ${ }^{2}$, Mario Tomazello Filho ${ }^{2}$, \\ José Roberto Soares Scolforo ${ }^{3}$, Francides Gomes Jr. ${ }^{2}$ \\ ${ }^{1}$ Eng $^{\mathrm{a}}$ Florestal, Dr ${ }^{\mathrm{a}}$., Depto. de Ciências Florestais, UFLA, Lavras, MG, Brasil - selvaticl@uol.com.br \\ ${ }^{2}$ Eng. Florestal, Dr., Depto. de Ciências Florestais, ESALQ/USP, Piracicaba, SP, Brazil - jotbrito@esalq.usp.br; \\ mtomazel@esalq.usp.br; fgomes@esalq.usp.br \\ ${ }^{3}$ Eng. Florestal, Dr., Depto. de Ciências Florestais, UFLA, Lavras, MG, Brasil - scolforo@ufla.br \\ Recebido para publicação: 17/05/2009 - Aceito para publicação: 07/10/2009
}

\begin{abstract}
Resumo
O trabalho teve por objetivo: verificar a influência da idade da árvore de candeia sobre os elementos anatômicos, teores de extrativos totais, lignina, cinzas e densidade básica, relacionado a duas condições de relevo ( $1.000 \mathrm{~m}$ e $1.100 \mathrm{~m}$ de altitude), em Aiuruoca, Minas Gerais. Em cada área de estudo foram amostradas 15 árvores distribuídas em 3 classes diamétricas, das quais foram retirados discos da base da árvore para determinações da idade, características anatômicas e densidade básica. Os fustes foram reduzidos na forma de cavacos onde foram retiradas amostras aleatórias de material para análises químicas. As características anatômicas das madeiras das duas áreas foram semelhantes, com variações na quantidade de vasos e tamanho de pontoações. As células de óleo apresentaram-se nas células do parênquima radial. A frequiência de vasos foi menor em árvores mais velhas. A densidade básica variou de $0,74 \mathrm{~g} / \mathrm{cm}^{3}$ na área com $1.000 \mathrm{~m}$ e $0,68 \mathrm{~g} / \mathrm{cm}^{3}$ para a área de $1.100 \mathrm{~m}$ de altitude, sendo maior em árvores mais velhas. Os teores de extrativos totais, lignina e cinzas, diferiram estatisticamente entre as madeiras das duas áreas estudadas. As árvores mais jovens apresentaram maior teor de material inorgânico; o teor de extrativos totais e de lignina, não foi influenciado pela idade.

Palavras-chave: Caracterização anatômica; composição química; densidade básica; Eremanthus erythropappus.
\end{abstract}

\begin{abstract}
Influence of altitude and stand age on basic density, anatomical, and chemical characteristics of candeia wood - Eremanthus erythropappus. This work aimed to study the influence of tree age and altitude on some anatomical elements characteristics (basic density, total extractives, lignin, and leached ashes) of candeia wood. The sampled trees were collected in the Aiuruoca County, Minas Gersis State, Brazil, in two different altitudes $(1,000$ and $1,100 \mathrm{~m}$ above sea level). From each altitude level 15 trees, enclosed in 3 diametric classes, were cut. Disks were taken from the trunk base of each tree in order to determine the age, the anatomical characteristics, and the basic density. Random samples from the trees trunks were collected for the chemical analyses. The wood density varied from 0.74 to $0.68 \mathrm{~g} / \mathrm{cm}^{3}$ in the trees collected at 1,000 and $1,100 \mathrm{~m}$ of altitude respectively, being higher in the older trees. The wood anatomical characteristics of both sites were similar, with some variations in the amount of vases and pit sizes. Oily cells were observed in the radial parenchyma tissue. The vases frequency was lower in the older trees. The content of total extractives, amount of lignin, and leached ashes were statistically different in the two studied sites. The youngest trees presented higher leached ashes content; total extractives and lignin were not influenced by tree age.

Keywords: Anatomical characterization; chemical components; basic density; Eremanthus erythropappus.
\end{abstract}

\section{INTRODUÇÃO}

A candeia (Eremanthus erythropappus (DC.) McLeisch), Asteraceae, árvore comum em Minas Gerais, destaca-se pela alta durabilidade de sua madeira e por possuir um óleo essencial, cujo princípio ativo, o alfa-bisabolol, é muito utilizado para a confecção de produtos cosméticos e fármacos, devido a 
suas propriedades antibacterianas, antimicóticas, dermatológicas e espasmódicas (PEREZ, 2001). Pesquisas indicam que a idade da árvore, quando da formação do lenho, independentemente da largura do anel de crescimento formado, também influencia a densidade da madeira. Dessa forma, o resultado final da densidade do lenho formado depende da relação entre a influência da largura do anel de crescimento e a influência da idade da árvore (PINHEIRO, 1999).

Siqueira (2002), estudando a composição química da madeira de candeia, encontrou um rendimento em óleo essencial de 2,3\%, e Rios (2003), trabalhando com otimização do rendimento em óleo essencial da madeira de candeia, apresentou um rendimento de $2,46 \%$. Segundo informações de produtores, o consumo de alfa-bisabolol no mercado brasileiro é estimado em 10 toneladas/ano, enquanto o volume consumido no exterior gira em torno de 80 toneladas/ano. Trata-se, portanto, de um mercado que movimenta 90 toneladas/ano, provenientes de mais de $11.000 \mathrm{~m}^{3}$ de madeira extraída e processada, a grande maioria de forma ilegal (IMAFLORA, 2007).

Os produtos obtidos da candeia alcançam preços relativamente altos no mercado. Por exemplo, os produtores rurais pagam de $\mathrm{R} \$ 35,00$ a $\mathrm{R} \$ 55,00$ pela dúzia de moirões. Já as indústrias que extraem o óleo essencial pagam entre $\mathrm{R} \$ 50,00$ e $\mathrm{R} \$ 90,00$ pelo metro estéreo de madeira. O óleo de candeia natural bruto e o alfa-bisabolol são comercializados nos mercados nacional e internacional, podendo alcançar de US\$ 27.00 a US\$ 60.00/kg, respectivamente (SCOLFORO et al., 2007). Por causa da sua enorme importância econômica, a espécie vem sendo intensamente explorada em suas regiões de origem, o que tem causado forte redução da sua área de ocorrência natural. Por conta desse fato, tem crescido o interesse na realização de estudos sobre a espécie e a obtenção de óleo de sua madeira (GALDINO, et al., 2003).

Por ser uma espécie que obteve destaque no setor florestal apenas nos últimos anos, pouco se sabe sobre a candeia quanto a seus aspectos tecnológicos. Como hipótese de trabalho, assume-se que a idade das árvores influencia nas características anatômicas, químicas e densidade em condições distintas de relevo. Nesse sentido, o objetivo deste trabalho foi verificar a influência da idade das árvores sobre algumas características anatômicas, a quantificação dos teores de lignina e extrativos totais, o material inorgânico e a determinação da densidade básica, em duas condições distintas de altitude do local de crescimento e em três classes diamétricas, de um povoamento nativo de candeia existente em Aiuruoca, Minas Gerais.

\section{MATERIAL E MÉTODOS}

\section{Seleção das árvores e coleta de madeira}

O material foi coletado na região do sul do estado de Minas Gerais, em Aiuruoca, na Fundação Matutu. O local de estudo não apresentava histórico registrado de prática anterior de manejo das árvores de candeia, sendo estas provenientes de duas partes distintas do candeial, com o solo caracterizado como Cambissolo. Foram abatidas cinco árvores para cada classe diamétrica, totalizando o corte de 30 árvores. As árvores foram coletadas tendo como referência três classes diamétricas distintas, com medidas tomadas no DAP (Classe 1: 5 a $10 \mathrm{~cm}$; Classe 2: 10,1 a 15,0 cm; Classe 3: 15,1 a $20 \mathrm{~cm}$ ).

\section{Determinação da idade}

$\mathrm{O}$ material foi retirado dos discos da base da árvore, de forma a garantir a presença de todos os anéis de crescimento. Foram retirados 2 discos de $2,5 \mathrm{~cm}$ de espessura da base de cada árvore, sendo um destinado para os estudos anatômicos e de densidade de massa básica da madeira e outro para a contagem dos anéis de crescimento. Os discos obtidos da base das árvores foram lixados, utilizando-se lixas de granulações $100,150,220,320$ e 400 . A contagem dos anéis foi procedida traçando-se duas retas marcando o diâmetro do disco. Com o auxílio de uma lupa, o número de anéis de crescimento foi contado, obtendo-se, assim, a idade da árvore. Essa metodologia foi adaptada de Baruso (1977) apud Perez (2001). Foi possível utilizar essa metodologia porque os anéis de crescimento eram bem delimitados.

\section{Preparo das amostras para anatomia}

De cada disco foram retiradas 2 amostras de madeira, entre a região do cerne e o alburno, em duas posições equidistantes, totalizando quatro corpos de prova de dimensões de $1,5 \times 1,5 \times 1,5 \mathrm{~cm}$ por árvore. Posteriormente, o amolecimento total dos corpos de prova foi realizado com aquecimento em água mais glicerina, na proporção água: glicerina de 1:2 v/v, durante três horas. As amostras estão 
incluídas na xiloteca do Laboratório de Anatomia da Madeira do Departamento de Ciências Florestais da UFLA.

\section{Análise anatômica da madeira}

Os cortes histológicos para a obtenção das lâminas permanentes foram feitos com o auxílio de um micrótomo de deslizamento, utilizando-se navalha de aço tipo C. A espessura de cada corte foi de $16 \mu \mathrm{m}$ nas superfícies transversal, longitudinal radial e tangencial. Utilizou-se o corante safranina. Foram realizadas descrições anatômicas das lâminas em relação a número, tamanho e quantidade dos elementos celulares, porosidade, arranjo dos vasos, agrupamento, frequência de vasos, diâmetro tangencial do lúmen dos vasos, tipos de placas de perfuração, tipo e formato das pontuações, tipo de parênquima axial, parênquima radial, largura, altura e frequência/ $\mathrm{mm}^{2}$ dos raios e estruturas especiais. A medição das fibras foi realizada em material dissociado, aplicando-se as Normas de Procedimentos em Estudos de Anatomia de Madeira do IBAMA, Brasília (CORANDIN; MUÑIZ, 1992), e normas da International Association of Wood Anatomists (IAWA, 1989). Para observação das células oleíferas, foram realizados outros cortes histológicos nos corpos de prova (para confecção de lâminas temporárias), que foram previamente saturados e passaram por um amolecimento brando com água e glicerina na proporção $1: 2 \mathrm{v} / \mathrm{v}$, por 30 minutos. Utilizou-se o Sudan III, um corante específico para lipídios, que permitiu a visualização do óleo. Para o preparo do corante, seguiu-se a metodologia proposta por Kraus; Arduin (1997).

\section{Análise química}

As 30 árvores retiradas nas áreas 1 e 2 foram transformadas em cavacos, dos quais foram retiradas amostras casualizadas, que foram transformadas em serragem com auxílio de moinho tipo Wiley. A granulometria da serragem obtida para análise química foi a que passasse na peneira de 40 mesh e ficasse retida na de 60 mesh. As análises químicas da madeira foram realizadas conforme as normas TAPPI (1998): T12wd-82 - (T12 os - 75 substituída pela T264) para preparação da madeira para análise química, incluindo procedimentos para remoção de extrativos; T13wd-74 - (T13 os - 54 combinada com T222) para lignina; e T15wd-80 - (T15 os - 58 combinada com T211) para constituintes inorgânicos (cinzas). Para cada árvore foram realizadas três repetições de análise.

\section{Determinação da densidade básica}

Foram retiradas duas cunhas em posições opostas de cada disco obtido da base da árvore, as quais foram utilizadas para a determinação da densidade básica da madeira, compondo duas amostras (cunhas) por árvore. A densidade de massa básica foi determinada de acordo com o método da balança hidrostática, descrito por Vital (1984).

\section{Análise estatística}

O delineamento foi inteiramente casualizado, com cinco repetições por classe de diâmetro. Os dados apresentaram homogeneidade de variância pelo teste de Cochran. Efetuou-se a análise de covariância para ajustar os valores da idade das árvores, e o teste Tukey ao nível de 5\% de probabilidade para as variáveis estudadas. O modelo estatístico utilizado foi:

$$
Y_{i j}=\mu+t_{i}+\beta\left(x_{i j}^{-}-x\right)+e_{i j}
$$

Em que: $Y_{i j}=$ observação relativa ao i-ésimo tratamento na j-ésima repetição;

$\mu=$ média geral;

$\mathrm{t}_{\mathrm{i}}=$ efeito do i-ésimo tratamento;

$\beta=$ coeficiente de regressão linear;

$\mathrm{x}_{\mathrm{ij}}=$ covariável (idade) medida no i-ésimo tratamento na j-ésima repetição;

$\mathrm{e}_{\mathrm{ij}}=$ erro experimental.

\section{RESULTADOS E DISCUSSÃO}

\section{Determinação da idade}

As tabelas 1 e 2 apresentam, respectivamente, o resumo da análise de variância da idade das árvores e os resultados dos valores médios por área e classe de diâmetro.

Observou-se que ocorreram diferenças estatisticamente significativas de idade entre as árvores de candeia para as áreas 1 e 2, e para as classes de diâmetro. 
Tabela 1. Análise de variância da idade das árvores de candeia.

Table 1. Analysis of variance of the age of the candeia trees.

\begin{tabular}{lcc}
\hline Fonte de Variação & GL & QM \\
\hline Classe de diâmetro & 2 & $120,73^{*}$ \\
Área & 1 & $1.385,66^{*}$ \\
Resíduo & 23 & 20,21 \\
\hline CV & 14,35 & \\
\hline GL: grau de liberdade; QM: quadrado médio; CV (\%): coeficiente de variação; * significativo ao \\
nível de 5\% de probabilidade pelo teste F.
\end{tabular}

Tabela 2. Valores médios de idade das árvores por classe de diâmetro e por tratamento.

Table 2. Average values of age of the trees for classroom of diameter and treatment.

\begin{tabular}{lccccc}
\hline & & Idade/ & CD & Idade/ & Área \\
\hline Área & CD & M & CV & M & CV \\
\hline 1 & 1 & $34 \mathrm{c}$ & 20,64 & & \\
& 2 & $40 \mathrm{~b}$ & 12,73 & $39,8 \mathrm{a}$ & 18,75 \\
& 3 & $45 \mathrm{a}$ & 9,26 & & \\
\hline 2 & 1 & $24 \mathrm{~b}$ & 11,41 & & 11,21 \\
& 2 & $24 \mathrm{~b}$ & 12,03 & $25 \mathrm{~b}$ & \\
& 3 & $27 \mathrm{a}$ & 6,04 & & \\
\hline
\end{tabular}

Área 1: 1000 m; Área 2: 1100 m; Classes: 1 (5,0-10,0 cm), $2(10,1-15,0 \mathrm{~cm}), 3(15,1-20,0 \mathrm{~cm})$; CV: Coef. variação (\%). As médias seguidas de uma mesma letra em uma mesma coluna não apresentam diferença significativa pelo teste Tukey ao nível de $5 \%$ de probabilidade.

O teste Tukey, para comparação das médias das idades de cada classe de diâmetro, mostrou que as árvores das classes de diâmetro 3 foram as que apresentaram maiores idades. Em termos estatísticos, na Área 2, as árvores das classes 1 e 2 podem ser consideradas iguais. A Área 1 foi a que apresentou árvores com maior idade, comparativamente às árvores da Área 2.

\section{Descrição microscópica da madeira}

Observando-se as lâminas (Figura 1), verificou-se a distribuição difusa e não-uniforme dos poros, a disposição radial dos vasos, bem como o seu agrupamento em múltiplos de quatro. A forma da seção dos vasos é arredondada. As pontuações intervasculares são arredondadas e caracterizam-se pelo arranjo alterno, sem ornamentações. As placas de perfuração são simples. O parênquima axial é classificado como paratraqueal escasso. Já o parênquima radial é homocelular, composto por células procumbentes. Os raios são unisseriados, com pequena ocorrência de raios bisseriados. As fibras são libriformes. Não foi observada a presença de estruturas estratificadas, floema incluso, sílica. Há a presença de máculas e fibras bifurcadas. Os dados biométricos dos elementos anatômicos com valores médios e estatísticos são apresentados nas tabelas 3 e 4 .
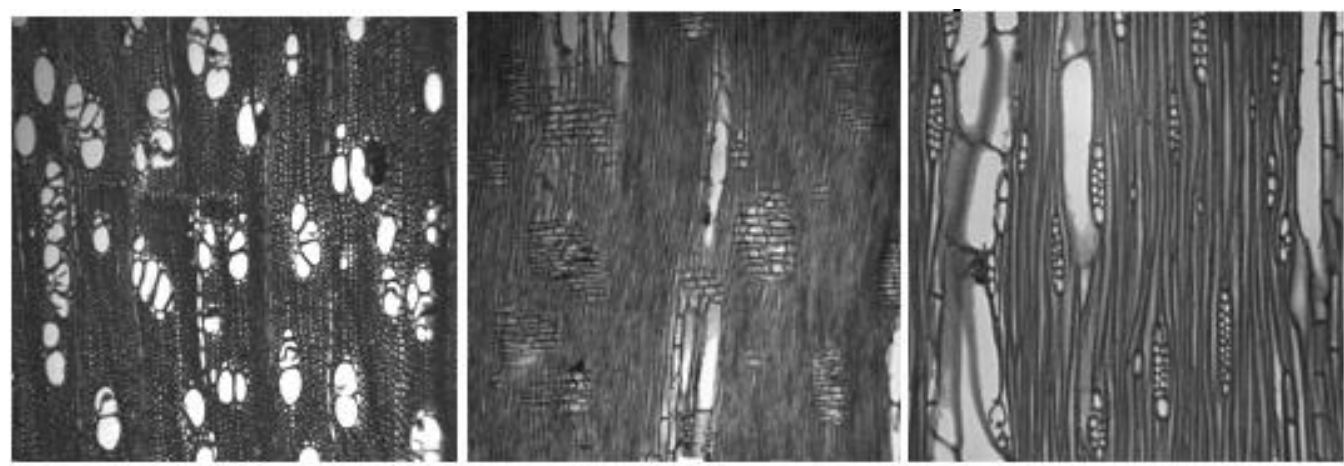

Figura 1. Cortes: Transversal, Longitudinal radial e Tangencial (4x).

Figure 1. Cutts: Transversal, Longitudinal radial and Tangential (4x). 
Tabela 3. Análise de variância dos elementos anatômicos da madeira de candeia.

Table 3. Analysis of variance of the anatomical elements of the candeia wood.

\begin{tabular}{|c|c|c|c|}
\hline & Fonte de variação & GL & QM \\
\hline \multirow[t]{5}{*}{ Frequência de vaso } & Classe de diâmetro & 2 & 11,62 \\
\hline & Área & 1 & $314,59 * *$ \\
\hline & Idade & 1 & 7,27 \\
\hline & Resíduo & 22 & 11,79 \\
\hline & $\mathrm{CV}$ & 17,38 & \\
\hline \multirow[t]{5}{*}{ Diâmetro de vaso } & Classe de diâmetro & 2 & 84,87 \\
\hline & Área & 1 & $549,63 * *$ \\
\hline & Idade & 1 & 207,25 \\
\hline & Resíduo & 22 & 62,76 \\
\hline & $\mathrm{CV}$ & 11,99 & \\
\hline \multirow[t]{5}{*}{ Pontuação } & Classe de diâmetro & 2 & $0,87 \times 10^{-1}$ \\
\hline & Área & 1 & $0,25 \times 10^{-1}$ \\
\hline & Idade & 1 & 0,11 \\
\hline & Resíduo & 22 & 0,20 \\
\hline & $\mathrm{CV}$ & 13,29 & \\
\hline \multirow[t]{5}{*}{ Altura do raio } & Classe de diâmetro & 2 & 1.496 \\
\hline & Área & 1 & 0,41 \\
\hline & Idade & 1 & 685,07 \\
\hline & Resíduo & 22 & 508,41 \\
\hline & $\mathrm{CV}$ & 16,85 & \\
\hline \multirow[t]{5}{*}{ Largura do raio } & Classe de diâmetro & 2 & $37,19^{*}$ \\
\hline & Área & 1 & 0,87 \\
\hline & Idade & 1 & 8,46 \\
\hline & Resíduo & 22 & 10,13 \\
\hline & $\mathrm{CV}$ & 18,33 & \\
\hline \multirow[t]{5}{*}{ Frequência do raio } & Classe de diâmetro & 2 & 1,09 \\
\hline & Área & 1 & 3,64 \\
\hline & Idade & 1 & 1,58 \\
\hline & Resíduo & 22 & 25,69 \\
\hline & $\mathrm{CV}$ & 15,46 & \\
\hline \multirow[t]{5}{*}{ Comprimento da fibra } & Classe de diâmetro & 2 & $7.811,76$ \\
\hline & Área & 1 & 11,87 \\
\hline & Idade & 1 & 245,07 \\
\hline & Resíduo & 22 & $2.522,89$ \\
\hline & $\mathrm{CV}$ & 8,44 & \\
\hline \multirow[t]{5}{*}{ Espessura da parede celular } & Classe de diâmetro & 2 & 0,45 \\
\hline & Área & 1 & 0,21 \\
\hline & Idade & 1 & 0,29 \\
\hline & Resíduo & 22 & 0,15 \\
\hline & $\mathrm{CV}$ & 8,55 & \\
\hline
\end{tabular}

Área 1: $1.000 \mathrm{~m}$; Área 2: $1.100 \mathrm{~m}$; Classes: 1 (5,0-10,0 cm), $2(10,1-15,0 \mathrm{~cm}), 3(15,1-20,0 \mathrm{~cm})$; GL: grau de liberdade; QM: quadrado médio; CV (\%): coeficiente de variação; * e **: significativo ao nível de $5 \%$ e $1 \%$ de probabilidade pelo teste $\mathrm{F}$.

Observou-se que a frequência média dos vasos da Área 1 diferiu estatisticamente da Área 2 pelo teste Tukey ao nível de $1 \%$ de probabilidade, ou seja, a Área 2 apresentou árvores possuindo madeira com mais vasos condutores do que a Área 1 . O diâmetro médio dos vasos das árvores da Área 1 também diferiu estatisticamente daquele apresentado pelas árvores da Área 2 pelo teste Tukey ao nível de 5\% de probabilidade, sendo considerados maiores nesta última. Quanto aos demais parâmetros anatômicos, não ocorreram diferenças estatisticamente significativas entre as madeiras das árvores das Áreas 1 e 2. Por outro lado, houve diferença estatisticamente significativa entre as médias nas classes de diâmetro, sendo a classe $3(20,12 \mu \mathrm{m})$ a que apresentou raios de maior largura do que nas classes $2(16,53 \mu \mathrm{m})$ e $1(15,42 \mu \mathrm{m})$. Conforme constatado, de maneira geral, em termos biométricos, as características anatômicas da madeira da Área 1 foram bastante semelhantes às observadas na Área 2. Mencione-se, no entanto, que pode ser observado na análise uma menor presença de máculas e fibras bifurcadas (o que caracteriza crescimento intrusivo) no material de maior altitude (Área 2). 
Tabela 4. Valores médios dos resultados biométricos dos elementos anatômicos.

Table 4. Average values of the biometrics results of the anatomical elements.

\begin{tabular}{|c|c|c|c|c|c|c|c|}
\hline Elemento anatômico & Área & CD & $\mathrm{M} / \mathrm{CD}$ & $\mathrm{CV}$ & M/Área & $\mathbf{C V}$ & Classificação * \\
\hline \multicolumn{8}{|c|}{ Vaso } \\
\hline Frequência & 1 & 1 & $13,38 \mathrm{a}$ & 9,07 & & & \\
\hline \multirow{5}{*}{$\left(\mathrm{N} / \mathrm{mm}^{2}\right)$} & & 2 & $13,83 \mathrm{a}$ & 14,16 & $13,19 \mathrm{a}$ & 14,29 & Poucos \\
\hline & & 3 & $12,49 \mathrm{a}$ & 20,83 & & & \\
\hline & 2 & 1 & $26,53 \mathrm{a}$ & 13,86 & & & \\
\hline & & 2 & $22,82 \mathrm{a}$ & 22,82 & $24,99 \mathrm{~b}$ & 11,05 & Numerosos \\
\hline & & 3 & $25,64 \mathrm{a}$ & 13,39 & & & \\
\hline Diâmetro & 1 & 1 & $54,12 \mathrm{a}$ & 9,65 & & & \\
\hline \multirow[t]{5}{*}{$(\mu \mathrm{m})$} & & 2 & $64,39 \mathrm{a}$ & 21,97 & $60,92 \mathrm{a}$ & 24,96 & Pequenos \\
\hline & & 3 & $66,84 \mathrm{a}$ & 10,54 & & & \\
\hline & 2 & 1 & $65,05 \mathrm{a}$ & 72,93 & & & \\
\hline & & 2 & $70,68 \mathrm{a}$ & 16,07 & $70,10 \mathrm{~b}$ & 25,74 & Pequenos \\
\hline & & 3 & $74,57 \mathrm{a}$ & 10,92 & & & \\
\hline Pontuações & 1 & 1 & $3,62 \mathrm{a}$ & 15,41 & & & Muito \\
\hline \multirow[t]{5}{*}{$(\mu \mathrm{m})$} & & 2 & $3,64 \mathrm{a}$ & 11,32 & $3,59 \mathrm{a}$ & 15,37 & pequenos \\
\hline & & 3 & $3,53 \mathrm{a}$ & 9,10 & & & \\
\hline & 2 & 1 & $3,32 \mathrm{a}$ & 14,30 & & & Muito \\
\hline & & 2 & $3,04 \mathrm{a}$ & 17,19 & $3,22 \mathrm{a}$ & 15,42 & pequenos \\
\hline & & 3 & $3,32 \mathrm{a}$ & 10,88 & & & \\
\hline \multicolumn{8}{|c|}{ Raio } \\
\hline \multirow{6}{*}{$\begin{array}{l}\text { Altura } \\
(\mu \mathrm{m})\end{array}$} & 1 & 1 & $130,66 \mathrm{a}$ & 9,18 & & & Extremamente \\
\hline & & 2 & $112,69 \mathrm{a}$ & 20,03 & $123,02 \mathrm{a}$ & 47,37 & baixos \\
\hline & & 3 & $121,25 \mathrm{a}$ & 14,41 & & & \\
\hline & 2 & 1 & $111,52 \mathrm{a}$ & 14,02 & & & Extremamente \\
\hline & & 2 & $153,95 \mathrm{a}$ & 11,46 & $142,38 \mathrm{a}$ & 43,88 & baixos \\
\hline & & 3 & $161,70 \mathrm{a}$ & 12,19 & & & \\
\hline Largura & 1 & 1 & $15,99 \mathrm{a}$ & 20,22 & & & Muito \\
\hline \multirow[t]{2}{*}{$(\mu \mathrm{m})$} & & 2 & $16,46 \mathrm{a}$ & 3,22 & $15,84 \mathrm{a}$ & 41,29 & Finos \\
\hline & & 3 & $15,19 \mathrm{a}$ & 18,24 & & & \\
\hline \multirow[t]{3}{*}{ Largura $(\mu \mathrm{m})$} & 2 & 1 & $15,54 \mathrm{a}$ & 7,91 & & & Muito \\
\hline & & 2 & $17,00 \mathrm{a}$ & 12,59 & $18,58 \mathrm{a}$ & 36,81 & Finos \\
\hline & & 3 & $23,20 \mathrm{a}$ & 14,51 & & & \\
\hline Frequência & 1 & 1 & $7,33 \mathrm{a}$ & 22,18 & & & \\
\hline \multirow{5}{*}{$\left(\mathrm{N} / \mathrm{mm}^{2}\right)$} & & 2 & $7,72 \mathrm{a}$ & 19,32 & $7,32 \mathrm{a}$ & 14,99 & Poucos \\
\hline & & 3 & $7,01 \mathrm{a}$ & 9,25 & & & \\
\hline & 2 & 1 & $6,24 \mathrm{a}$ & 17,72 & & & \\
\hline & & 2 & $6,85 \mathrm{a}$ & 10,37 & $6,72 \mathrm{a}$ & 16,02 & Poucos \\
\hline & & 3 & $7,08 \mathrm{a}$ & 10,84 & & & \\
\hline \multicolumn{8}{|c|}{ Fibra } \\
\hline \multirow{6}{*}{$\begin{array}{l}\text { Comprimento } \\
(\mu \mathrm{m})\end{array}$} & 1 & 1 & $623,91 \mathrm{a}$ & 6,04 & & & \\
\hline & & 2 & $530,24 \mathrm{a}$ & 12,37 & $601,10 \mathrm{a}$ & 20,56 & curtas \\
\hline & & 3 & $625,74 \mathrm{a}$ & 8,78 & & & \\
\hline & 2 & 1 & 588,36 a & 3,01 & & & Muito \\
\hline & & 2 & $572,19 \mathrm{a}$ & 9,73 & $589,19 \mathrm{a}$ & 17,75 & curtas \\
\hline & & 3 & $607,04 \mathrm{a}$ & 9,00 & & & \\
\hline \multirow{6}{*}{$\begin{array}{l}\text { Espessura da } \\
\text { parede celular } \\
(\mu \mathrm{m})\end{array}$} & 1 & 1 & $4,29 \mathrm{a}$ & 6,29 & & & Parede \\
\hline & & 2 & $4,20 \mathrm{a}$ & 2,16 & $4,40 \mathrm{a}$ & 19,63 & delgada a \\
\hline & & 3 & $4,70 \mathrm{a}$ & 10,79 & & & espessa \\
\hline & 2 & 1 & $4,29 \mathrm{a}$ & 7,72 & & & Parede \\
\hline & & 2 & $4,87 \mathrm{a}$ & 10,35 & $4,65 \mathrm{a}$ & 20,22 & delgada a \\
\hline & & 3 & $4,82 \mathrm{a}$ & 5,65 & & & espessa \\
\hline
\end{tabular}

M: média; CV: coeficiente de variação (\%); Área 1: $1000 \mathrm{~m}$; Área 2: $1100 \mathrm{~m}$; CD: classes de diâmetro - 1 (5,0-10,0 cm), $2(10,1-$ $15,0 \mathrm{~cm}), 3(15,1-20,0 \mathrm{~cm})$. Médias seguidas de uma mesma letra em uma mesma coluna não apresentam diferença significativa pelo teste Tukey ao nível de 5\% de probabilidade. * Classificação: Norma IAWA (1989) e IBAMA (1992). 
Segundo Costa et al. (2003), os elementos de vaso estão associados à eficácia e garantia do transporte de água pela planta, sendo diretamente afetados pelas variações na disponibilidade desse insumo. Os mesmo autores ainda afirmam que estudos de anatomia em plantas provenientes de ambientes mesofíticos e xerofíticos demonstram que os elementos de vaso são maiores e ocorrem em menor número nas plantas em que o suprimento hídrico é adequado. Já nos vegetais sujeitos a déficit hídrico os elementos de vaso são menores, mais agrupados e bastante numerosos. Isso confirma os resultados encontrados para a madeira das árvores da Área 2, onde há um maior déficit hídrico (Tabela 1) do que na Área 1. A influência da altitude sobre a anatomia da madeira também pode ser constatada a partir do momento em que, com o aumento da altitude, os elementos de vaso tornam-se mais numerosos, mais estreitos e mais curtos, as fibras tornam-se mais curtas e os raios se tornam mais baixos, conforme relatam Costa et al. (2003).

Tomando como base a norma IAWA (1989) para classificação de estruturas secretoras produtoras de óleos e mucilagens, notou-se, após a observação microscópica no plano transversal e radial, em ambas as áreas e classes de diâmetro, que o óleo da candeia é provavelmente produzido por células de parênquima radial, também conhecidas como células de parênquima especiais, conforme a coloração mais acentuada após a aplicação do corante Sudan III (Figura 2). Costa (2003) também cita que as células oleíferas são encontradas nos parênquimas radial e axial ou entre as fibras. Para o caso específico da candeia, os resultados aqui encontrados confirmam os resultados de Mello (1950) e Araújo (1944), cujos trabalhos encontraram, no raio, células oleosas de cheiro ativo para a madeira da espécie.

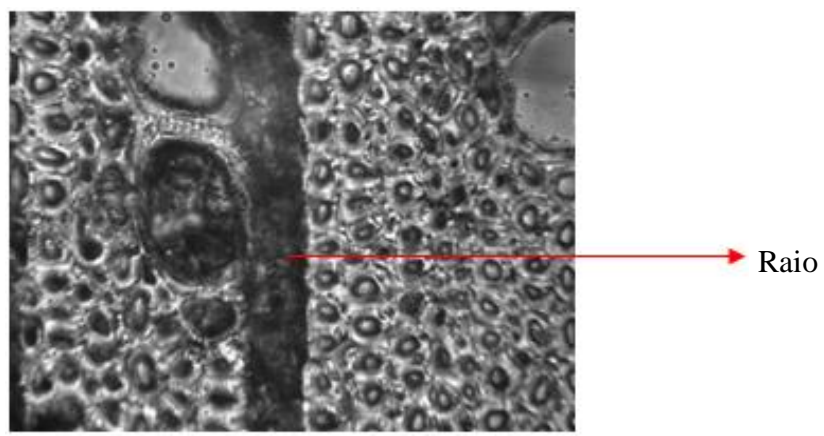

Figura 2. Corte transversal (40x).

Figure 2. Transversal cut (40x).

\section{Composição química}

Os valores médios e estatísticos das análises químicas da madeira de candeia são apresentados nas tabelas 5 e 6 .

A quantidade de extrativos totais da madeira das árvores da Área 1 diferiu estatisticamente da madeira das árvores da Área 2 pelo teste F, ao nível de 5\% de probabilidade, sendo maior para a primeira área, que corresponde às árvores ocorrendo em baixada. Pode-se constatar que, para ambas as áreas, os teores de extrativos foram maiores para os indivíduos com menores diâmetros, o que pode estar relacionado a uma maior atividade fisiológica dos indivíduos mais jovens e ao fato de essa madeira possuir um óleo essencial, que é um tipo de extrativo. As árvores, quando mais jovens, possuem um maior metabolismo e com isso uma maior produção de material a ser armazenado pela planta como reserva para sua proteção e crescimento. Em plantas adultas, esse metabolismo tende a se estabilizar até a senescência (SJOSTROM, 1981). Siqueira (2002). trabalhando com Eremanthus erythroppapus no município de Carrancas, MG, encontrou valores de extrativos totais para a madeira com idade próxima a 20 anos de $20,89 \%$, e para casca, de $43,73 \%$.

A quantidade de lignina da madeira das árvores da Área 1 diferiu estatisticamente da madeira das árvores da Área 2 pelo teste $\mathrm{F}$ ao nível de $5 \%$ de probabilidade. Os teores de lignina se mostraram maiores na Área 2. Os valores médios para a lignina estão próximos aos obtidos por Siqueira (2002), que encontrou valores de 28,59\% para o cerne de árvores de candeia. Em ambas as áreas, os teores de lignina se mostraram maiores para os indivíduos com maiores diâmetros, sobretudo na Área 1. Como as áreas apresentam diferenças entre os solos, pode-se dizer, qualitativamente, que os nutrientes e a umidade do solo podem ter afetado o desenvolvimento das árvores nas áreas estudadas e, por conseguinte, a formação 
dos constituintes químicos da madeira. Árvores que possuem crescimento mais lento, ou seja, que se desenvolvem em sítios pouco produtivos, tendem a apresentar baixo teor de lignina na composição da madeira (GONÇALEZ et al., 2009, apud BIERMANN, 1996).

Tabela 5. Resumo da análise de variância da composição química da madeira de candeia.

Table 5. Summary of the analysis of variance the chemical composition of the candeia wood.

\begin{tabular}{lccc} 
& Fonte de Variação & GL & QM \\
\hline Extrativos totais & Classe de diâmetro & 2 & $10,74^{*}$ \\
& Área & 1 & $1,24^{*}$ \\
& Idade & 1,01 \\
& Resíduo & 3,52 \\
\cline { 2 - 3 } & CV & 11,18 & 0,78 \\
\hline Lignina & Classe de diâmetro & 2 & $17,14 *$ \\
& Área & 1 & 8,99 \\
& Idade & 1 & 5,37 \\
\cline { 2 - 3 } & Resíduo & 22 & $0,15 \times 10^{-2}$ \\
Cinzas & CV & 8,70 & $0,28 \times 10^{-3}$ \\
& Classe de diâmetro & 2 & $0,95 \times 10^{-2}$
\end{tabular}

Área 1: $1.000 \mathrm{~m}$; Área 2: $1.100 \mathrm{~m}$; Classes: $1(5,0-10,0 \mathrm{~cm}), 2(10,1-15,0 \mathrm{~cm}), 3(15,1-20,0 \mathrm{~cm})$; GL: grau de liberdade; QM: quadrado médio; CV (\%): coeficiente de variação; * significativo ao nível de $5 \%$ de probabilidade pelo teste $\mathrm{F}$.

Tabela 6. Composição química - Valores médios por área e classe de diâmetro (\%).

Table 6. Chemical composition - Average values for area and classroom of diameter (\%).

\begin{tabular}{|c|c|c|c|c|c|c|}
\hline & & & Média/CD & & Média/Áre & \\
\hline & Área & CD & $\mathbf{M}$ & $\mathrm{CV}$ & $\mathbf{M}$ & $\mathrm{CV}$ \\
\hline Extrativos & 1 & 1 & $19,06 \mathrm{a}$ & 7,23 & & \\
\hline \multirow[t]{5}{*}{ Totais } & & 2 & $16,13 \mathrm{ab}$ & 19,35 & $17,89 \mathrm{a}$ & 12,97 \\
\hline & & 3 & $15,95 \mathrm{~b}$ & 5,69 & & \\
\hline & 2 & 1 & $17,53 \mathrm{a}$ & 13,92 & & \\
\hline & & 2 & $15,58 \mathrm{ab}$ & 10,82 & $15,87 \mathrm{~b}$ & 13,10 \\
\hline & & 3 & $14,52 \mathrm{~b}$ & 4,98 & & \\
\hline \multirow[t]{6}{*}{ Lignina } & 1 & 1 & $24,86 \mathrm{a}$ & 9,56 & & \\
\hline & & 2 & $25,45 \mathrm{a}$ & 15,64 & $25,91 \mathrm{a}$ & 9,62 \\
\hline & & 3 & $27,59 \mathrm{a}$ & 3,66 & & \\
\hline & 2 & 1 & $26,67 \mathrm{a}$ & 7,96 & & \\
\hline & & 2 & $27,79 \mathrm{a}$ & 7,91 & $27,20 \mathrm{~b}$ & 8,22 \\
\hline & & 3 & $27,14 \mathrm{a}$ & 8,80 & & \\
\hline \multirow[t]{6}{*}{ Cinzas } & 1 & 1 & $0,470 \mathrm{a}$ & 12,76 & & \\
\hline & & 2 & $0,432 \mathrm{a}$ & 17,71 & $0,45 \mathrm{a}$ & 17,83 \\
\hline & & 3 & $0,440 \mathrm{a}$ & 23,03 & & \\
\hline & 2 & 1 & $0,528 \mathrm{a}$ & 17,55 & & \\
\hline & & 2 & $0,558 \mathrm{a}$ & 21,90 & $0,50 \mathrm{a}$ & 17,26 \\
\hline & & 3 & $0,417 \mathrm{a}$ & 12,35 & & \\
\hline
\end{tabular}

Área 1: 1000 m; Área 2: 1100 m; CD: Classes de diâmetro: 1 (5,0-10,0 cm), 2 (10,1-15,0 cm), 3 (15,1-20,0 cm); CV: coeficiente de variação $(\%)$. Médias seguidas de uma mesma letra em uma mesma coluna não apresentam diferença significativa pelo teste Tukey ao nível de $5 \%$ de probabilidade. 
A quantidade de cinzas na madeira das árvores da Área 1 não diferiu estatisticamente da Área 2 pelo teste $\mathrm{F}$ ao nível de $5 \%$ de probabilidade, o mesmo sendo constatado para as classes de diâmetro. Siqueira (2002) encontrou valores da quantidade de cinzas na madeira de candeia de $0,30 \%$ no cerne e $1,35 \%$ na casca.

\section{Densidade básica}

A tabela 7 apresenta o resumo da análise de variância para os resultados da densidade básica da madeira de candeia.

Tabela 7. Resumo da análise de variância para a densidade de massa básica da madeira de candeia.

Table 7. Summary of the analysis of variance for basic density of the candeia wood.

\begin{tabular}{lcc}
\hline Fonte de variação & GL & QM \\
\hline Classe de diâmetro & 2 & $0,33 \times 10^{-3}$ \\
Área & 1 & $0,66 \times 10^{-2} *$ \\
Idade & 1 & $0,21 \times 10^{-3}$ \\
Resíduo & 22 & $0,18 \times 10^{-2}$ \\
\hline CV (\%) & 6,06 & \\
Ârea 1: 1000 m; Área 2: 1100 m; GL: grau de liberdade; QM: quadrado médio; CV (\%):
\end{tabular}

coeficiente de variação; * significativo ao nível de $5 \%$ de probabilidade pelo teste $\mathrm{F}$.

As diferenças entre as médias de densidade básica da madeira de candeia foram significativas para as áreas estudadas ao nível de 5\% de probabilidade. A densidade foi maior para a madeira das árvores da Área 1 (Tabela 8). Não foram significativas as diferenças entre as médias de densidade básica entre as classes de diâmetro.

A tabela 8 mostra os resultados médios de densidade básica, considerando-se os tratamentos e as classes diamétricas.

A densidade básica da madeira apresentando-se com maiores valores em todas as classes de diâmetro da Área $1(1000 \mathrm{~m})$ pode estar relacionada ao fato de suas madeiras apresentarem menores diâmetros de vasos e, consequentemente, menor porosidade (Tabela 4), de tal forma que essa variação pode ser explicada pela influência da anatomia da madeira da candeia e da altitude. Castelo et al. (2008), ao analisar a influência de diferentes sítios em árvores de Pinus com idades de 14, 16 e 18 anos, constataram que as madeiras provenientes do sítio com taxa de crescimento mais elevada e com textura mais argilosa mostraram-se com tendência a terem maiores valores para densidade, largura de fibras e diâmetros do lume.

Tabela 8. Valores médios por tratamento da densidade básica da madeira de candeia $\left(\mathrm{g} / \mathrm{cm}^{3}\right)$.

Table 8. Average values for treatment of the basic density of the candeia wood $\left(\mathrm{g} / \mathrm{cm}^{3}\right)$.

\begin{tabular}{lccccc}
\hline & & Média & CD & Média & Área \\
\hline Área & CD & M & CV & M & CV \\
\hline 1 & 1 & $0,745 \mathrm{a}$ & 6,49 & & 7,66 \\
& 2 & $0,746 \mathrm{a}$ & 10,19 & $0,742 \mathrm{a}$ & \\
\hline 2 & $0,733 \mathrm{a}$ & 6,30 & & \\
& 1 & $0,695 \mathrm{a}$ & 4,27 & & \\
& 2 & $0,672 \mathrm{a}$ & 4,40 & $0,687 \mathrm{~b}$ & \\
& 3 & $0,694 \mathrm{a}$ & 5,32 & & \\
\hline
\end{tabular}

Área 1: 1000 m; Área 2: 1100 m; Classes: 1 (5,0-10,0 cm), 2 (10,1-15,0 cm), 3 (15,1-20,0 cm); CV: Coef. variação (\%). Médias seguidas de uma mesma letra em uma mesma coluna não apresentam diferença significativa pelo teste Tukey ao nível de $5 \%$ de probabilidade.

Os resultados estão de acordo com os encontrados por Chagas et al. (2005), que, trabalhando com a candeia, encontraram as densidades médias do lenho variando entre 0,44 e $0,73 \mathrm{~g} / \mathrm{cm}^{3}$, com tendência de maior valor em árvores com diâmetro acima de $27 \mathrm{~cm}$. Com a densidade básica variando entre 0,687 e $0,742 \mathrm{~g} / \mathrm{cm}^{3}$, pode-se considerar a madeira de candeia como sendo muito pesada, de acordo com as normas de classificação da Forest Products Laboratory (1973). 
Perez et al. (2004) encontraram valores para densidade básica da candeia entre $0,60 \mathrm{~g} / \mathrm{cm}^{3} \mathrm{e}$ $0,78 \mathrm{~g} / \mathrm{cm}^{3}$, com predominância desse valor entre 0,63 e $0,71 \mathrm{~g} / \mathrm{cm}^{3}$, apresentando um comportamento para esses valores decrescente no sentido base-topo, sendo que nas classes de diâmetro variando entre $12,5 \mathrm{~cm}$ e $27,5 \mathrm{~cm}$ a densidade tendeu a aumentar seu valor das árvores de menor diâmetro para as de maior diâmetro.

\section{Associações dos elementos anatômicos com sua densidade de massa básica e idade da madeira}

A tabela 9 apresenta os valores das correlações (Pearson) dos caracteres estudados com a idade de suas árvores.

Tabela 9. Coeficiente de correlações de Pearson entre caracteres estudados e idade.

Table 9. Coefficient of correlations of Pearson between the studied characters and the age.

\begin{tabular}{lc}
\hline Elementos anatômicos & Idade \\
\hline Densidade de massa básica & $0,420^{* *}$ \\
Frequência do vaso & $-0,687^{* *}$ \\
Diâmetro do vaso & $-0,082$ \\
Pontuações & 0,385 \\
Altura do raio & $-0,288$ \\
Largura do raio & $-0,228$ \\
Frequência do raio & 0,154 \\
Comprimento da fibra & 0,158 \\
Espessura da parede celular da fibra & $-0,120$ \\
Extrativos totais & 0,128 \\
Lignina & $-0,013$ \\
Cinzas & $-0,427^{*}$ \\
\hline * * $*$ significativo a 5\% e 1\% de probabilidade pelo Teste t respectivamente. &
\end{tabular}

Observando-se a tabela 9, para as árvores estudadas, a idade das árvores apresentou uma correlação significativa com a densidade básica, mostrando que, quanto mais velhas as árvores, maior a densidade básica da madeira. A densidade é uma característica influenciada pela anatomia do lenho, e conforme se observa, mesmo havendo pouca correlação dos elementos anatômicos com a idade, no caso específico do presente estudo a frequência de vasos reduz-se significativamente com o aumento da idade da árvore. Ainda observando-se a tabela 9, os extrativos totais e a lignina não apresentaram correlação com a idade. Entretanto, no caso da lignina, a quantidade foi maior em árvores de menor idade (25 anos). Isso é explicado pelo fato de que as espécies mais jovens tendem a possuir uma maior proporção de madeira juvenil, que é mais rica em lignina do que a madeira madura, porém no caso da candeia isso não foi constatado, o que mostra que a diferença obtida entre as áreas pode estar sendo influenciada mais pelas condições do local de crescimento da espécie do que pela idade da mesma. O mesmo também podese dizer sobre o fato de não haver influência da idade nos extrativos totais.

$\mathrm{O}$ teor de cinzas apresenta uma correlação negativa com a idade, significando que quanto menor a idade das árvores de candeia, maior será a porcentagem do teor de material inorgânico na composição química dessa espécie, para o material avaliado. Provavelmente isso seja decorrente do maior metabolismo e atividade fisiológica das plantas mais jovens, que exigiria a maior presença de componentes minerais. $\mathrm{O}$ crescimento das plantas é grandemente influenciado por fatores ambientais (climáticos, edáficos e topográficos), e a interação desses fatores com as plantas expressa a qualidade do sítio, levando árvores de uma mesma espécie a apresentarem, em função do sítio, crescimentos diferentes (GONÇALEZ et al., 2009).

Trugilho et al. (1996), estudando a madeira de Eucalyptus saligna, concluíram que existe uma tendência de estabilização nos valores de extrativos totais, lignina e holocelulose em árvores mais velhas, pois as espécies mais jovens tendem a possuir uma maior proporção de madeira juvenil, que é mais rica em lignina do que a madeira madura. Andrade (2006), estudando a influência da idade nas características tecnológicas da madeira de Pinus taeda L., verificou a interação da idade com o teor de lignina, teor de extrativos totais e material inorgânico, observando que, com o aumento da idade, houve um aumento significativo dos teores de extrativos totais e o teor de lignina e material inorgânico apresentaram tendência inversa. 


\section{CONCLUSÕES}

- As características anatômicas, químicas e de densidade da candeia foram influenciadas pela idade das árvores em condições distintas de relevo.

- As características anatômicas das madeiras das duas áreas foram semelhantes, com variações na quantidade de vasos maior em árvores mais velhas.

- As células de óleo da candeia apresentaram-se nas células do parênquima radial (raios).

- Quanto à composição química, verificou-se que o teor de extrativos totais da madeira de candeia foi maior para as árvores crescendo em região de menor altitude.

- Por sua vez, os teores de lignina e de cinzas foram maiores na área mais elevada.

- As árvores mais jovens apresentaram maior teor de cinzas, enquanto o teor de extrativos totais e a lignina não foram influenciados pela idade das árvores estudadas.

- Com relação à densidade básica da madeira da candeia, essa espécie pode ser considerada como uma madeira muito pesada. Verifica-se ainda que essa característica é influenciada pela idade, apresentando maior valor na área de menor altitude e em árvores mais velhas, porém não foram observadas diferenças entre as classes de diâmetro.

- O conhecimento das características da madeira de candeia estudado pode permitir auxílio no manejo, práticas silviculturais e melhoramento dessa espécie para usos específicos, de forma a melhorar o desenvolvimento das árvores de candeia para a região de Aiuruoca.

\section{REFERÊNCIAS}

ANDRADE, A. S. de. Qualidade da madeira, celulose e papel em Pinus taeda L.: influência da idade e classe de produtividade. Dissertação (Mestrado na área de Ciências Florestais) - UFPR, Curitiba, PR, 2006. $107 \mathrm{p}$.

ARAÚJO, L. C. Vanillosmopsis erythropappa (DC.) Sch. Bip.: sua exploração florestal. Rio de Janeiro: Escola Nacional de Agronomia, 1944. 54 p. (Tese para o concurso de Professor de Horticultura e Silvicultura).

CASTELO, P. A. R.; MATOS, J. L. M. de; DEDECEK, R. A.; LAVORANTI, O. J. Influência de diferentes sítios de crescimento sobre a qualidade da madeira de Pinus taeda. Floresta, Curitiba, PR, v. 38, n. 3, jul./set. 2008 .

ChAGAS, M. P.; TOMAZELlO FILHO, M.; LISI, C. S.; BRITO, J. O.; GUIMARÃES, E. R. Caracterização dos anéis de crescimento e densidade da madeira de árvores de candeia Eremanthus erythropappus pela densitometria de raios X. Santos: INAC, 2007. 1 v.

CORANDIN, V. T. R.; MUÑIZ, G. I. B. Normas de procedimentos em estudos de anatomia de madeira: I Angiospermae, II Gimnospermae. Brasília: IBAMA, 1992, 19 p. (LPF Série técnica 15).

COSTA, C. G.; CALlADO, C. H.; CORANDIN, V. T. R.; GUERREIRO, S. M. C. Xilema. In Anatomia vegetal. Viçosa: UFV, 2003. cap. 5, p. 129-141.

FOREST PRODUCTS LABORATORY - Standard terms for describing wood. USDA. Forest Service. Forest Products Laboratory Research Paper, Madison, n. 171, p. 1-10, 1973.

GALDINO, A. P. P.; BRITO, J. O.; GARCIA, R. F.; SCOLFORO, J. R. Estudo sobre o rendimento e a qualidade do óleo essencial de candeia (Eremanthus sp.) e a influência das diferentes origens da sua madeira. Simpósio Brasileiro de Óleos Essenciais - Diagnósticos e Perspectivas, 2., 2003, Campinas Anais... Campinas, 3-5, nov. 2003, p. 31.

GONÇALEZ, J. C.; VIEIRA, F. S.; CAMARGOS, J. A. A.; ZERBINI, N. J. Influência do sítio nas propriedades da madeira de Pinus caribaea var. hondurensis. Cerne, Lavras, v. 15, n. 2, p. 251-255, abr./jun. 2009.

IAWA Comittee, 1989 - IAWA list of microscopic features for hardwood identification; IAWA Bulletin, v. 10 , n. 3, p. 221-332. 
IMAFLORA - Instituto de Manejo e Certificação Florestal e Agrícola. Certificação FSC, um diferencial para a indústria cosmética e farmacêutica. 2007 (Boletim, 19).

KRAUS, J. E.; ARDUIN, M. Manual básico de métodos em morfologia vegetal. Rio de Janeiro: Editora Edur, UFRRJ, 1997. 198 p.

MELLO, E. C. Estudo dendrológico de essências florestais do Parque Nacional de Itatiaia e os caracteres anatômicos de seus lenhos. Rio de Janeiro: Ministério da Agricultura, 1950. p. 64. (Boletim, 2).

PEREZ, J. F. M. Sistema de manejo para candeia (Eremanthus erythropappus (D.C) Mac. Leish). 71 p. 2001. Dissertação (Mestrado na área de Ciências Florestais) - Universidade Federal de Lavras, Lavras, 2001.

PEREZ, J. F. M.; SCOLFORO, J. R. S.; OLIVEIRA, A. D.; MELlO, J. M.; BORGES, L. F. R.; CAMOLESI, J. F. Sistema de manejo para candeia - Eremanthus erythropappus (DC.) MacLeish - a opção do sistema de corte seletivo. Revista Cerne, Lavras, v. 10, n. 2, 257-273, jul./dez. 2004.

PINHEIRO, A. L. Considerações sobre taxonomia, filogenia, ecologia, genética, melhoramento florestal e a fertilização mineral e seus reflexos na anatomia e qualidade da madeira. Viçosa: SIF, 1999. 144 p.: il.

RIOS, P. D’Angelo. Otimização do rendimento em óleo essencial de candeia (Eremanthus erythropappus). Universidade Federal de Lavras, Monografia, 29 p., 2003.

SCOLFORO, J. R. S.; PEREZ, J. F. M.; MELLO, J. M.; OLIVEIRA, A. D.; CAMOLESI, J. F.; BORGES, L. F. R.; ACERBI JÚNIOR, F. W. Estimativas de volume, peso seco, peso de óleo e quantidade de moirões para a candeia (Eremanthus erythropappus (DC.) MacLeish). Revista Cerne, Lavras, v. 10, n. 1, 87-102, jan./jun. 2004.

SCOLFORO, J. R. S.; OLIVEIRA, A. D.; DAVIDE, A. C.; MELLO, J. M.; ACERBI JÚNIOR, F. W. Manejo sustentado da candeia (Eremanthus erythropappus (DC.) McLeisch e Eremanthus incanus (Less.) Less.). 2007 (Relatório Técnico Científico). <http://www.nucleoestudo.ufla.br/nemaf/candeia /relatorio_projeto.pdf>.

SIQUEIRA, D. Caracterização química da casca e madeira de candeia (Eremanthus erythropappus). Monografia. Lavras, UFLA, 2002. 21 p.

SJOSTROM, E. Wood Chemistry, Academic Press, 1981.

TAPPI TEST METHODS. Fibrous materials and pulp testing t1-t270. paper and paperboard testing. v. 1, Atlanta: Tappi Press, 1998. t400-t550.

TRUGILHO, P. F.; LIMA, J. T.; MENDES, L. M. Influência da idade nas características físicomecânicas e anatômicas da madeira de Eucalyptus saligna. Revista Cerne, cidade, v. 2, n. 1, p. 97-111, 1996.

VITAL, B. R. Métodos de determinação da massa específica da madeira. Viçosa: Sociedade de Investigações Florestais, 1984. 21 p. (Boletim Técnico, 1). 